\title{
后扶贫时代 Z 县返贫风险因素的探究及对策提出
}

\section{Research on risk factors of returning to poverty in $\mathrm{Z}$ county in post-poverty-alleviation era and countermeasures}

\author{
李鹤斌 孙小琳 贾虚 杨舜铃 佟林珊 \\ Hebin Li Xiaolin Sun Xu Jia Shunling Yang Linshan Tong \\ 沈阳化工大学 辽宁 沈阳 110000 \\ Shenyang Institute of Chemical Technology Shenyang Liaoning 110000
}

\begin{abstract}
摘 要: 我国全面进入小康社会之后,广大贫困县打赢了这场艰苦的脱贫攻坚战,但是随之而来的却是脱贫人口的返贫问题 愈演愈烈。本文对后扶贫时代 Z 县返贫的风险因素进行实证分析，准确识别扶贫开发进程中的脱贫人口面临的政策导向返 贫、自身发展导向返贫、自身能力导向返贫与环境因素返贫等隐患, 并运用社会科学统计软件( SPSS)对其形成的原因进行分 析运算、数据挖掘、预测分析并最终提供解决方案。
\end{abstract}

\begin{abstract}
After China entered the Xiaokang, the vast number of poor counties won the tough battle against poverty, but the problem of returning poor people to poverty became more and more serious. This paper makes an empirical analysis on the risk factors of returning to poverty in $\mathrm{Z}$ county in the post-poverty-alleviation era, accurately identifying the hidden dangers facing the poverty-stricken population in the process of poverty alleviation and development, such as policy-oriented return to poverty, self-development-oriented return to poverty, self-capability-oriented return to poverty and environmental factors return to poverty, and use the social science statistics software (SPSS) to analyze the causes of its formation, data mining, prediction analysis and ultimately provide solutions.
\end{abstract}

关键词:后扶贫时代; $Z$ 县; 返贫

Keywords : Post-poverty era; z county; back to poverty

DOI : $10.36012 /$ emr.v2i6.2990

\section{1.研究背景}

2020 年是我国全面打赢脱贫攻坚战收官之年。2020 年 11 月，贵州省剩余 9 个贫困县序列标志着全国 832 个贫困 县全部脱贫摘帽。 2020 年 12 月 3 日, 习近平总书记在中共 中央政治局常委会上指出, 经过 8 年持续奋斗, 我们如期完 成了新时代脱贫攻坚目标任务, 现行标准下农村贫困人口全 部脱贫, 贫困县全部摘帽, 清除了绝对贫困和区域性整体贫 困, 近 1 亿贫困人口实现脱贫, 取得了令全世界刮目相看的 重大胜利[1]。虽然我国目前消除了绝对贫困, 但仍有很多人民 受返贫因素困扰。因此, 在扶贫项目工作取得圆满进展, 在保 证高质量实现脱贫目标的同时，应及时建立完善的防止返贫 长效机制，健全相关考核、督导机制及约束激励机制，以期为 我国扶贫工作作出指导 ${ }^{[2]}$ 。

尽管从宏观层面看, 我国返贫率并不算高, 但是在决战 决胜脱贫攻坚和未来的相对贫困治理阶段, 仍然要把防止返
贫置于更突出的位置, 堵住可能存在的返贫风险点 ${ }^{[3]}$ 。

\section{2.致贫及返贫风险因素分析}

本文采取的是实证主义研究方法, 运用 SPSS 社会科学 分析软件, 对 $\mathrm{Z}$ 县 180 名贫困人口进行问卷调查。

\section{1 信度分析}

调查组根据当地情况设置了相关问卷并展开调查。通过 spss 软件对回收的 180 份问卷进行信度系数分析后, 问卷得出的 克隆巴赫系数为 0.647 , 因系数在 0.6 以上, 说明量表的信度 良好。

\section{2 调查对象 (见表 1 )}

2.3 研究假设 H1: 因教育原因使脱贫人口的返贫程度加 深, H2 : 因疾病原因使得脱贫人口的返贫概率加大,H3: 政府 的政策持续性会影响人口返贫, $\mathrm{H} 4$ : 贫困人口本身的技术能 力对返贫有影响,H5: 自然灾害会对人口返贫有影响.

【基金项目】2020 年辽宁省大学生创新创业训练计划资助项目, 项目编号: S202010149040

【作者简介】李鹤斌(2000-), 男, 汉, 辽宁沈阳人, 本科生, 研究方向: 沈阳化工大学公共事业管理专业。 
表 1

\begin{tabular}{|c|c|c|c|c|c|c|c|}
\hline 指标 & 指标内容 & 总数 & 百分比 & 指标 & 指标内容 & 总数 & 百分比 \\
\hline \multirow{3}{*}{$\begin{array}{l}\text { 身 } \\
\text { 份 }\end{array}$} & 农民 & 114 & $62.98 \%$ & 性别 & 男 & 77 & $42.54 \%$ \\
\hline & 学生 & 36 & 19.89 & & 女 & 104 & $57.46 \%$ \\
\hline & 上班族 & 31 & 17.12 & \multirow{2}{*}{$\begin{array}{l}\text { 文 化 } \\
\text { 水平 }\end{array}$} & \multirow{2}{*}{ 小学 } & \multirow{2}{*}{57} & $31.49 \%$ \\
\hline \multirow{4}{*}{$\begin{array}{l}\text { 年 } \\
\text { 龄 }\end{array}$} & 15-20 岁 & 50 & $27.62 \%$ & & & & \\
\hline & 21-30 岁 & 85 & $46.96 \%$ & & 初中 & 89 & $49.17 \%$ \\
\hline & 31-45 岁 & 33 & $18.23 \%$ & & 高中 & 23 & $12.71 \%$ \\
\hline & 45 岁以上 & 13 & $7.18 \%$ & & 大学 & 12 & $6.63 \%$ \\
\hline
\end{tabular}

\section{4 相关性分析}

(1)求学原因、教育原因会导致贫困户返贫。家中求学的 孩子越多, 则负担的学习成本就会更重, 学习成本过重会间 接的影响贫困户重返贫困状态。因此求学的因素与返贫呈正 相关关系, 家中求学孩子越多, 该家庭重返贫困的几率越大。

(2)政策的不连续性会影响贫困户返贫。政策的不连续 性主要表现为社会性政策返贫,是扶贫开发过程中的社会保 障等社会管理领域所引发的返贫风险。当地人民脱贫之后面 临政策不持续的风险，二者之间是显著的正相关关系。

\begin{tabular}{|c|c|c|c|}
\hline \multicolumn{4}{|c|}{ 表 2} \\
\hline & & $\begin{array}{l}\text { 9、您家的贫困程度 } \\
\text { 是? }\end{array}$ & $\begin{array}{l}\text { 7、你家有几个 } \\
\text { 孩子在读书? }\end{array}$ \\
\hline \multirow{3}{*}{$\begin{array}{l}\text { 9、您家的 } \\
\text { 贫困 程度 } \\
\text { 是? }\end{array}$} & 皮尔逊相关性 & \multirow[b]{3}{*}{180} & $329 * *$ \\
\hline & 显著性(双尾) & & 000 \\
\hline & 个案数 & & 180 \\
\hline \multirow{3}{*}{$\begin{array}{l}\text { 7、你家有 } \\
\text { 几个孩子 } \\
\text { 在读书? }\end{array}$} & 皮尔逊相关性 & $329 * *$ & \multirow[t]{2}{*}{1} \\
\hline & 显著性(双尾 & 000 & \\
\hline & 个案数 & 180 & 180 \\
\hline
\end{tabular}

(3)疾病原因、脱贫户自身能力的缺失与自然灾害等因 素都会影响贫困户返贫。除此之外,脱贫人口的医疗成本、自 身的发展能力与当地的自然灾害因素都会影响脱贫户返贫。 一般情况下, 有沉重疾病负担的家庭会更容易返贫。脱贫户 自身能力越差, 则返贫的风险越大。自然灾害频发则会增大 返贫的概率。

\section{5 根据以上分析, 我们可以将 $Z$ 县贫困人口返贫} 的的原因归纳为四大类:一是政策性返贫,二是自身因能 力和技术限制返贫，三是自身因发展问题导致返贫，四是自然 灾害返贫。

\section{3. 对策}

\section{1 增加政策的稳定性,加强政府支持力度}

首先要加强公共基础设施建设。扶贫开发过程对于基础 设施的建设的帮扶在贫困人口脱贫之后可能不在帮扶。贫困 地区仍然面临公共基础设施薄弱情况, 水电, 交通, 网络等方
面并未得到全面有效解决, 基础设施仍需大力建设扶持; 其 次要解决社会保障乏力问题, 应尽快打破旧的社会保障二元 体系, 开发完善社会新保障制度的同时还应该进一步提高社 会整体保障质量, 提高社会保障覆盖率面积, 尽可能使更多 的人享受到社会保障带来的好处, 加快最低社会保障制度建 设的进程, 提高公共服务水平, 加快保险市场发育发展;

\section{2 精准识别重病人口,推进医疗资源下沉}

扶贫不能一概而论, 既要兼顾普遍性更不能忽略特殊情 况。对于因病致贫的情况，应该根据原有的建档立卡逐个了 解调查, 以此为基础精准识别需要重点帮扶的对象。而对于 偏远山区而言, 因病致贫的情况更是大量存在。这需要针对 当地居民进行身体健康排查, 尤其是针对高龄, 空巢贫困患 者, 以此来评估其返贫风险, 做好预防措施。发现因病致贫的 对象之后, 还应大力推进医疗资源下沉。

\section{3 发展特色旅游, 走可持续生态发展之路}

$\mathrm{Z}$ 县具有丰富的旅游资源。全县具有典型的喀斯特地 貌, 峰林峰丛遍布, 溶洞奇特; 湿润的气候为动植物提供了良 好的生存条件, 名木古树繁多;美丽的格必河穿行于山谷之 间, 孕育了各族人民, 沿途风光如画; 古朴的民族风情和丰富 的地方特产令人惊奇和赞叹。众多的自然风景和人文景观集 中于格必河一带, 成为独具特色的省级风景名胜区, 极具开 发价值 ${ }^{[4]}$ 。依据此资源打造特色产业优势, 可以根据自身经验 特色, 于现有基础上深化特色产业发展, 立足自身, 挖掘自身 特色, 扬长避短, 依据自身特色资源发展本地区的特色文化 旅游, 以多种不同方式推动三大产业稳步增长, 不仅可以促 进自身发展, 更可以提高居民生活质量水平, 推动当地经济 发展。在发展当地特色旅游的同时,应注意保护当地环境。首 先应强化宣传, 提高全民环保意识,保护当地的生存发展环 境。其次加大投入,为当地环境生态保护提供充足的资金保 障,通过多方面多主体资金投入当地环保项目,在开发旅游 项目的情况下,保证当地居民生活环境良好,在促进当地经 济发展的同时注重当地环境保护, 以此当地发展提供良好发 展环境, 促进良性循环。

\section{参考文献}

[1] 程明, 吴波, 潘琳. “后 2020”时代我国农村返贫的生成机理、治 理困境与优化路径[J].岭南学刊,2021(01):63-70.

[2] 丁昱棋.建立防止返贫长效机制的问题及对策研究[J].中小企业 管理与科技(中旬刊),2021(02):142-143.

[3] 章文光.脱贫攻坚决战决胜期需要注意的几个问题——基于建 档立卡实地监测调研的思考 $[\mathrm{J}]$.中共中央党校(国家行政学院) 学报,2020,24(02):43-51.

[4] 冯开禹.发展生态旅游走旅游脱贫之路——紫云县旅游资源的 开发利用[J].安顺师范高等专科学校学报,2002(04):39-41. 